\title{
Earthworms and rice straw enhanced soil bacterial diversity and promoted the degradation of phenanthrene
}

\author{
Ali Mohamed Elyamine $e^{1,2,3}$ and Chengxiao $\mathrm{Hu}^{1,2^{*}}$
}

\begin{abstract}
Background: Since the industrial revolution, the contamination of agricultural soils by polycyclic aromatic hydrocarbons (PAHs) has increasingly become of serious global environmental concern and poses a huge threat to human beings and natural ecosystems. Microbial degradation is a proved technology mostly used to depollute polycyclic aromatic hydrocarbon (PAH) in the environment. However, very limited information is available regarding the interaction of earthworms with rice straw on the soil microbial community and the degradation of phenanthrene. This study was performed to enlighten the rice straw and earthworms' interaction on soil bacterial abundance and structure and phenanthrene removal.

Results: Result about functional gene information revealed that both rice straw and earthworm enhanced phenanthrene degradation. Subsequently, both Shannon diversity index $\left(r^{2}=-0.8807, p<0.001\right)$ and bacterial 16S rRNA genes $\left(r^{2}=-0.7795, p<0.001\right)$ negatively correlated with the remaining phenanthrene concentration in soil. The application of both rice straw and earthworms in soil had the lowest ratio of soil remaining phenanthrene concentration $(0.16 \pm 0.02)$, the highest Shannon diversity index $(6.45 \pm 0.2)$ and the highest bacterial $16 \mathrm{~S}$ rRNA genes. This implied that both earthworms and rice straw might improve the phenanthrene metabolism by increasing soil bacteria diversity. The abundance of genera Pseudomonas, Luteimonas, Rhodanobacter, Sphingomonas, Gemmatimonas, Flavobacterium, and Leifsonia was significantly increased in the presence of both earthworms and rice straw and was found to negatively correlate with the remaining phenanthrene concentration in soil.

Conclusion: Based on these results, this study offers clear and strong evidences that the positive interaction between earthworms and rice straw could promote phenanthrene degradation in soil. These finding will improve our understanding on the importance of the natural resources forsaken and how they can interact with the soil macroand microorganisms to change soil structure and enhance PAH degradation in soil.
\end{abstract}

Keywords: Rice straw, Eisenia fetida, Microbiome, Phenanthrene-bacterial metabolism, Aporrectodea caliginosa

\section{Background}

The anthropologic activities such as mining activities [14], vehicle circulation and urbanization [1], industrialization, and heat generation by moderate industrial

\footnotetext{
*Correspondence: hucx@mail.hzau.edu.cn

${ }^{1}$ Key Laboratory of Arable Land Conservation (Middle and Lower Reaches of Yangtze River), Ministry of Agriculture, Research Center of Micro-elements, College of Resource and Environment, Huazhong Agricultural University, Wuhan 430070, Hubei, China

Full list of author information is available at the end of the article
}

incineration [21] constitute the main source of polycyclic aromatic hydrocarbons (PAHs). PAHs are a class of hazardous chemicals well known with carcinogenicity, teratogenicity, mutagenicity and toxicity properties [46]. Among the polycyclic aromatic hydrocarbon, phenanthrene is the simplest composed by three-fused ring compound [40], present in PAH-contaminated soil, and used as model by several researchers for remediation process [21].
Springer Open

(c) The Author(s) 2020. This article is licensed under a Creative Commons Attribution 4.0 International License, which permits use, sharing, adaptation, distribution and reproduction in any medium or format, as long as you give appropriate credit to the original author(s) and the source, provide a link to the Creative Commons licence, and indicate if changes were made. The images or other third party material in this article are included in the article's Creative Commons licence, unless indicated otherwise in a credit line to the material. If material is not included in the article's Creative Commons licence and your intended use is not permitted by statutory regulation or exceeds the permitted use, you will need to obtain permission directly from the copyright holder. To view a copy of this licence, visit http://creativeco mmons.org/licenses/by/4.0/. 
Given the benefits of simple technology without secondary pollution, microbial degradation has become the primary means to depollute the environment polluted by organic pollutant. This technology not only proved to be effective, but also a low-cost and eco-friendly strategy $[7,30]$. Microorganisms contain degrading genes that can effectively degrade and catabolize the target pollutant $[8,17,28]$. For efficient and profitable bioremediation of PAHs, both bio-augmentation involving resistant microorganism strains capable of degrading various pollutants in soil [39] and bio-stimulation which attempts to increase exogenous and indigenous soil microbial activity [24] are commonly used.

Subsequently, another low-cost efficient and environmentally friendly remediation technology is the use of earthworms. They were reported to accelerate the removal of organic contaminant such as herbicides [34], polychlorinated biphenyl (PCBs) [36], PAHs [9] and crude oil [35]. Earthworms enhance the transference of soil microorganisms within different soil layers and are implicated in the degradation of soil organic matter. Truly, during the feeding process of earthworms, organic and mineral composites are mingled in their gut and turned down as casts on the soil surface or along burrows [26]. This phenomenon might increase the microbial population and improve the connection between soil microorganisms and pollutants [22]. However, although the approach integrating earthworm-soil microbial interaction to remove PAHs in soil appeared to be compromising, most of PAH-removal study such as $[3,4,7]$ involved plant system and very limited information is available regarding the integration of rice straw in the microbial community change and the degradation of PAHs.

Rice straw, as a dissimilar material, was reported to be effective, not only as biosorbent to reducing heavy metals in aquatic environment $[19,33]$, but also as organic fertilizer, which can be used for PAH removal. The use of organic fertilizers to remove PAH in the soil was reported to be of great success [41] since there is an adjacent correlation between soil microbial community and the degradation of pollutant [25]. Furthermore, through the humification and the mineralization effect of microorganisms, the abundance of micro-fauna attached to plant residues improved with decomposition of organic matter $[48,49]$.

Thus, the use of earthworms and rice straw could be an effective technology to promote phenanthrene degradation in the soil by enhancing phenanthrene-degrading bacteria abundance and activities. The main goal of this study was to explore how earthworms and rice straw interaction could change the structure of soil bacterial community and enhance phenanthrene degradation in the contaminated soil. The hypothesis of the present study is that the application of rice straw and earthworms could create different distinctive phenanthrenedegrading bacteria community and would consequently improve the removal of phenanthrene in soil. Result of this study will improve our understanding on the importance of the neglected natural resources and how the rice straw can interact with the soil macro- and microorganisms to change soil structure and enhance PAH degradation in soil.

\section{Materials and methods Soil proprieties}

Soil from 0 to $20 \mathrm{~cm}$ was collected at Huazhong Agricultural University (HZAU) test site $\left(30^{\circ} 28^{\prime} 26^{\prime \prime} \mathrm{N}, 114^{\circ}\right.$ $20^{\prime} 51^{\prime \prime} \mathrm{E}$ ) in Wuhan, China, during the autumn season (October 2017), by removing the litter layer. Soil samples were then transferred to the greenhouse, air dried and sieved $(2 \mathrm{~mm})$. The characteristics of the used soil can be found in our previous studies $[12,13]$.

\section{Collection and treatment of earthworms and rice straw}

Two ecologically different earthworm species, i.e. Eisenia fetida and Aporrectodea caliginosa were used for the experiment. The first one is an epigeic species, well known for its fast growth, rapid productivity and organic waste conversion efficiency [23]. In contrast, the second specie is endogeic, known with its higher bioturbation property [11]. The two species were selected in the installed earthworms breeding site at HZAU described in our previous studies [12,13]. Straw of Oryza sativa was also collected at the agricultural field of HZAU. Once in the laboratory, distilled water was used to wash the collected straw three times before drying it at $60{ }^{\circ} \mathrm{C}$ and crushing it with grinder to obtain a fraction with particle size between 1 and $2 \mathrm{~mm}$ [13].

\section{Experimental design}

Three kilogram of air-dried soil was placed in ceramic pots $(22 \times 21 \mathrm{~cm})$ for the test experiment. An analytically pure acetone was used to dissolve phenanthrene (97\% purity) as described by [10] and [51]. A final concentration of $50 \mathrm{mg} / \mathrm{kg}$ of phenanthrene was produced by spiking the obtained solution thoroughly with the soil. To assess whether the solvent acetone presents or not any effect on soil microbial population, the negative control treatment $(+\mathrm{Ck} /-\mathrm{Ck})$ was prepared using clean soil and acetone only.

The experiment had four treatments with three replicates, including the positive control treatment $(\mathrm{P})$ prepared with neither rice straw nor earthworms; PS treatment with rice straw only; PW treatment with earthworms only; and PSW treatment with both earthworms 
and rice straw. Crushed straw (to $2 \mathrm{~mm}$ particle size, $50 \mathrm{~g} / 3 \mathrm{~kg}$ soil) was applied on the soil surface of the PS and PSW treatments as described in [13]. Ten epigeic and endogeic adults and healthy individuals' species were randomly selected and treated for the experiment. To void the gut content of earthworms, the selected individual's earthworms were regrouped, rinsed with DI water and placed on moist paper for $24 \mathrm{~h}$ before placing them on the soil of PW and PSW treatments for 30 experimental days.

\section{Soil collection after 30 experimental days and analysis}

The soil samples were collected after scattering the first top 2-cm level to eliminate any possible surfaces influences.

\section{Determination of phenanthrene concentration}

Phenanthrene concentration in soil was determined using the protocol described in our previous study [12]. Brief, soil sample was ground and mixed with 1.5 times its wet weight of $\mathrm{Na}_{2} \mathrm{SO}_{4}$ to a fine powder. The detail of the protocol can be found in [51]. High-performance liquid chromatography (HPLC) (HITACHI Chromaster 5300, Hitachi Beijing Tech Information Systems Co., Ltd) was used to measure phenanthrene concentration. The certified standard material NIST1647 Priority Pollutant Polycyclic Aromatic Hydrocarbon (PPPAH) with the recovery rate of $95 \pm 3 \%$ was used for the accuracy and analysis quality of phenanthrene measurements.

\section{Quantification of soil bacterial abundance}

The quantification of soil bacterial abundance was performed by following the protocol in [44] with slight modification. Total genomic DNA of soil sample was extracted using a PowerSoil Kit (MoBio Laboratories, Solana Beach, CA, United States) strictly following the manufacturer's instruction. High-quality DNA were amplified by polymerase chain reaction (PCR) amplification as described in $[18,44]$, using $338 \mathrm{~F}\left(5^{\prime}\right.$-ACTCCT ACGGGAGGCAGCAG-3') and 518R (5'-ATTACCGCG GCTGCTGG-3') universal primers. PCR amplifications were performed in a PRISM ${ }^{\circledR} 7500$ rapid real-time PCR system.

\section{Determination of bacterial community}

Illumina MiSeq sequencing and universal primers 515F (5'-GTGCCAGCMGCCGCGG-3') and 806R (5'-GGA CTACHVGGGTWTCTAAT-3') were used to amplify the 16S rRNA genes V4-V5 region of the 16S rRNA gene for the analysis of soil microbial community by Sangon Biotec Institute (Shanghai, China). Purified PCR amplicons were pooled in equimolar and paired-end sequenced $(2 \times 250 \mathrm{bp})$ on the Illumina MiSeq platform in Shanghai, China. The detail of the protocol used for the whole process can be found in [2].

\section{Computational analysis}

Quantitative Insights into Microbial Ecology (QIIME Version 1.8.0) was used to demultiplex and quality-filter the raw fastq files. Then the filtered sequences were grouped into Operational Taxonomic Units (OTUs) clustered with a $97 \%$ similarity cutoff using UPARSE software (version 7.0.1001). UCHIME 4.2.4.0 was used to identify and remove chimeric sequences. The RDP Classifier (version 2.12) 16S rRNA (ribosomal) database was employed to analysis the taxonomy of each $16 \mathrm{~S}$ rRNA gene sequence using a confidence threshold of $97 \%$. A bioinformatics technique, PICRUSt was used to predict and generate a table of functional genes from 16S rRNA data. Prior to metagenome prediction, the OTUs of $16 \mathrm{~S}$ rRNA sequences were normalized by PICRUSt. PCoA of the UniFrac distances in QIIME Version 1.8.0 was performed to visualize the distance matrix.

\section{Statistical analysis}

Bacterial abundance was $\log 10$-transformed to produce a normal distribution. ANOVA using SPSS 20 statistical software was used for statistical analysis. To evaluate similarities among different treatments, ANOSIM was used. Permutational analysis of variance (PERMANOVA) was used to evaluate the effects of compartment, rice straw and earthworm's effects on bacterial communities. To discover the specific genes which can explain the different abundance in rice straw and earthworm treatments, linear effect size (LEfSe) method was used to identify significant genes belonging to phylum to genus. Then linear discriminant analysis (LDA) was used to reduce the dimensions and estimate the effect sizes of significant different of specific bacteria (expressed by LDA score). Relative abundance was calculated by the following the equation and the Shannon index was calculated to describe $\alpha$ diversity and the richness of the microbial community.

$$
\mathrm{RA}=\frac{\text { OTUs allied to the same phylogenic group }}{\text { Total number of OTUs }} .
$$

\section{Results}

\section{Degradation of phenanthrene and its products/} metabolites

The result of the negative control $(+\mathrm{Ck} /-\mathrm{Ck})$ showed that the inoculation of acetone does not present any effect on soil microbial composition (Additional file 1: Figs. S1, S2 and S3). After 30 days of incubation, the phenanthrene concentration in soil was $17.76 \mathrm{mg} / \mathrm{kg}, 9.77 \mathrm{mg} / \mathrm{kg}$ and 
$8.46 \mathrm{mg} / \mathrm{kg}$ in straw (PS), earthworms (PW) and earthworms + straw (PSW) treatments, respectively (Table 1). Phenanthrene concentration in rice straw treatment (PS) was significantly different $(p<0.05)$ compared to the control (P). Moreover, the introduction of earthworms, considerably $(p<0.001)$ enhanced phenanthrene reduction. Out of a total of $50 \mathrm{mg} / \mathrm{kg}$ of phenanthrene initially added in the soil, $64 \%, 80 \%$ and $83 \%$ was removed in rice straw (PS), earthworms (PW) and in earthworms + straw (PSW) treatments, respectively. Additionally, PW and PSW treatments showed a phenanthrene remaining ratio significantly $(p<0.001$, Table 1$)$ lower compared to the control $(P)$.

Predicted functional genes from 16S rRNA data were carried out to determine the presence of possible degradation products/metabolites or other functional genes involved in the degradation/metabolism of organic pollutants. Therefore, a quantitative comparison of COGs among treatments was performed to identify functions among the treatment (Fig. 1). Almost all the significantly changed individual COGs fitting to the categories of lipid metabolism, metabolism of cofactor, carbohydrate metabolism, amino acid metabolism and vitamins, and energy metabolism were enriched in all treatments. Compared to the control $(P)$ genes involved in carbohydrate metabolism were enriched remarkably in the three others treatments. However, the application of rice straw (PS) or earthworms, either in single (PW) or dual (PSW) treatment did not manifest any significance difference regarding to the functional diversity.

Figure 2 shows different organic products identified in the different soil samples. Although the profile of all the treatments appeared to be similar, the abundance of genes involved in the dual (PSW) treatment was more pronounced compared to that in the single treatment. Compared to the control treatment $(P)$, naphthalene degradation, phallic and salicylic acid metabolism, biophenol, fluorobenzene, benzoate, and ethylbenzene degradation were more enriched in PS, PW and PSW.

\section{Changes of soil microbial Abundance and diversity of soil bacteria}

Throughout the 16S rRNA genes sequencing, a total of 518,488 bacterial sequences and 41,936 OTUs were identified in the present work. OTUs which differed among the four treatments was significantly $(p<0.01)$ higher in PW treatment and highest $(p<0.001)$ in PSW compared to the control (Table 1). A Venn diagram for OTU number ranging from 5740 (P treatment) to 7067 (PSW treatment) among the four treatments is presented in Fig. 3. 3522 OTUs over 25,840 were shared by all the four treatments. However, in 7067 OTUs identified in PSW treatment 4111, 4035 and 3684 were shared with PW, PS and $P$, respectively. The richness estimated by Shannon diversity index indicated that the bacterial diversity increased significantly $(p<0.05)$ in PSW and PW treatments in the phenanthrene-contaminated soil (Table 1). Soil microbial population increased significantly in earthworms (PW) treatment; however, the increase was exceptionally more important in the combined (PSW) treatment. Although bacterial diversity in straw treatment (PS) was not significantly different compared to the control, the numbers of OTUs were significantly increased. Yet, compared to straw treatment (PS), bacterial community was 1.12and 1.37-fold higher in earthworm (PW) and combined (PSW) treatment, respectively. The highest soil bacterial diversity was observed in PSW treatment.

To assess whether there was correlation between both bacterial Shannon diversity index and soil bacterial 16S rRNA genes with the remained phenanthrene concentration in soil, correlation test was performed. It was found that both Shannon biodiversity index $\left(r^{2}=-0.8807\right.$, $p<0.001)$ and bacterial 16S rRNA genes $\left(r^{2}=-0.7795\right.$, $p<0.001)$ negatively correlated with the remained phenanthrene concentration in soil (Fig. 4 and Additional file 1: Table S2). Since the dual rice straw and earthworms introduction in soil (PWS) had the lowest remained phenanthrene concentration ratio $(0.16 \pm 0.02$; tableau $1)$, the highest Shannon index $(6.45 \pm 0.2)$ and the highest

Table 1 Phenanthrene remained concentration in soil, phenanthrene remained ratio, estimates of bacterial abundance and diversity indices in different treatments

\begin{tabular}{lllll}
\hline Treatment & $\begin{array}{l}\text { PHE concentration } \\
\text { remained }\end{array}$ & PHE remained ratio $r$ & Seq_sequences & OTUs_num \\
\hline$P$ & $29.52 \pm 0.35$ & $0.59 \pm 0.06$ & 101,650 & 9429 \\
PS & $17.76 \pm 0.85^{*}$ & $0.35 \pm 0.04^{*}$ & 130,882 & $9695^{*}$ \\
PW & $9.77 \pm 0.46^{* * *}$ & $0.19 \pm 0.08^{* * *}$ & 142,878 & $10,906^{* *}$ \\
PSW & $8.46 \pm 0.86^{* * *}$ & $0.16 \pm 0.09^{* * *}$ & 143,078 & $6.38 \pm 0.7^{*}$ \\
\hline
\end{tabular}

Data are the mean of three replicate \pm SD and were compared by Duncan's multiple range tests. Seq_num is the quality number of samples reads and OTU_num is the number of $16 \mathrm{~S}$ rRNA sequences OTUs obtained by sample clustering and normalized PICRUSt. Different asterisks *, ** and ${ }^{* * *}$ in the same column (4 values) indicate significant difference at $p<0.05, p<0.01$ and $p<0.001$, respectively 


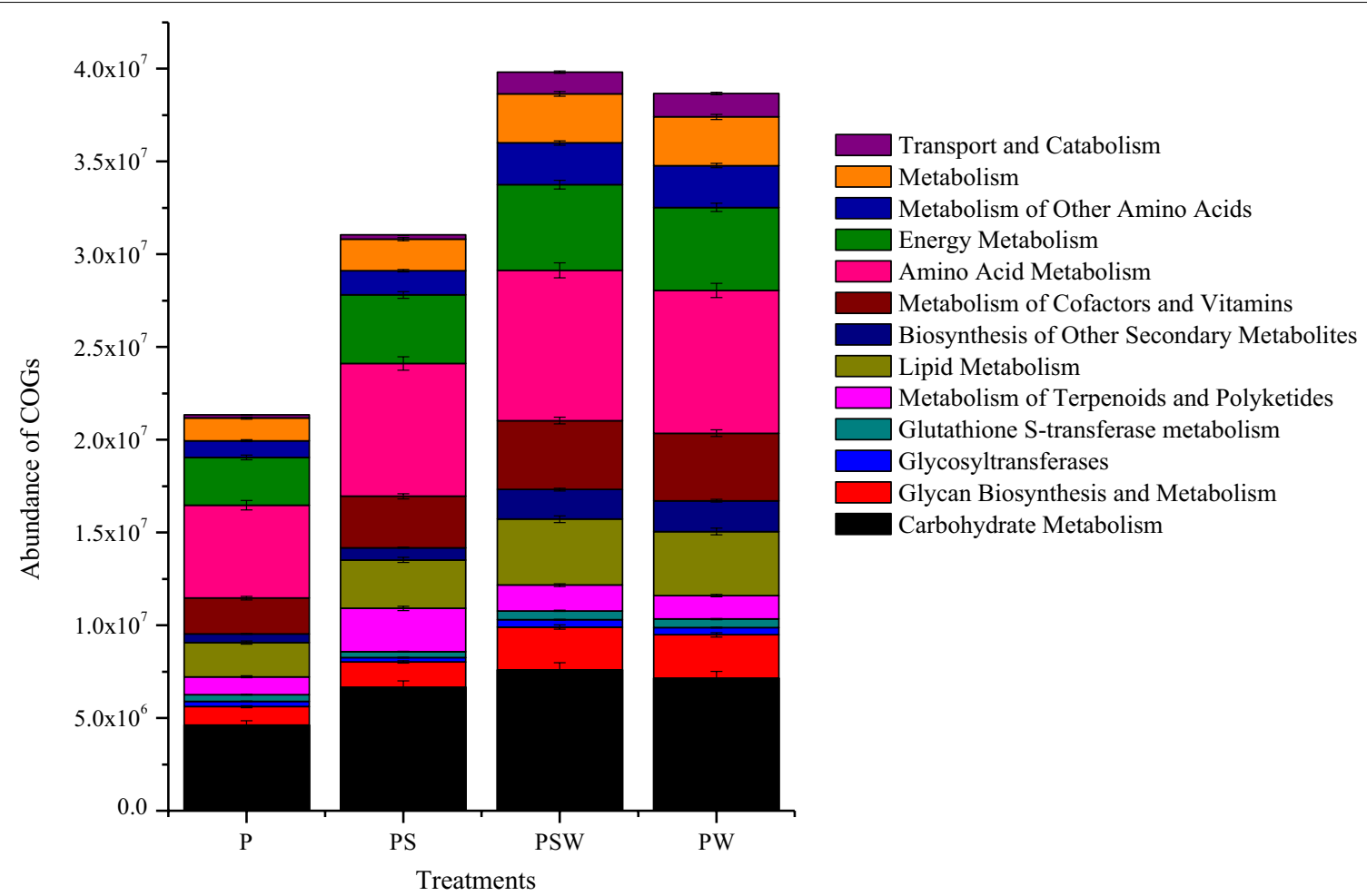

Fig. 1 Clusters Orthologous Group (COG) categories for the soil samples. The horizontal axis represents the number of each sample, the vertical axis represents the abundance ratio and the error bar represented the standard. The color corresponds to the function name and different color width indicates different function abundance. $(\mathrm{P}=$ control treatment, $\mathrm{PS}=$ rice straw treatment, $\mathrm{PW}=$ earthworms treatment and $\mathrm{PSW}=\mathrm{combined}$ earthworms and straw treatment) in three replicates

bacterial reads for $16 \mathrm{~S}$ rRNA genes, this implied that both earthworms and rice straw might improve the phenanthrene metabolism by increasing soil bacteria biomass and diversity.

\section{Community composition}

The relative abundance of specific bacteria was explored at class level (Table 2). The richness index was similar in the control $(P)$ and straw (PS) treatments and differed to that in earthworms (PW) and combined (PSW) treatments. Shannon index revealed that the population repartition in PW and PSW was similar. In a global view, no significant difference $(p>0.05)$ in bacterial OTUs and species richness were observed between the four treatments. However, in relative abundance, earthworms significantly increased the abundance of Proteobacteria which was represented by alpha, gamma, beta and delta-proteobacteria counting more than $50 \%$ of the total represented classes. Sphingobacteria, Actinobacteria, Gemmatimonadetes, Flavobacteria and Cytophagia were the next represented classes with $25 \%, 20 \%, 12 \%$, $7 \%$ and $7 \%$, respectively. The abundance of Gamma-proteobacteria $\left(\mathrm{r}^{2}=-0.81, \quad p<0.01\right)$, Alpha-proteobacteria $\left(r^{2}=-0.74, p<0.01\right)$, Gemmatimonadetes $\left(r^{2}=-0.61\right.$, $p<0.05)$, Flavobacteria $\left(r^{2}=-0.581, p<0.05\right)$ and Actinobacteria $\left(r^{2}=-0.52, p<0.05\right)$ classes was found to negatively correlate with the remained concentration of phenanthrene in soil.

The bacterial community was further analyzed at the genus level (Table 2). Earthworms and rice straw addition significantly increased the relative abundance of Sphingomonas (34.7\%), Luteimonas (24.63\%), Rhodanobacter (21.34\%), Gemmatimonas (15.65\%), Pseudomonas (9.87\%), Flavobacterium (9.43\%), Leifsonia (8.98\%) and Sediminibactium $(8.76 \%)$, which were the dominant genus of the OTUs in each treatment. In addition, for all represented genus, relative abundance in PSW and PW treatments was particularly marked $(p<0.05)$. Pearson correlation coefficient among these most represented genus showed that the abundance of Pseudomonas $\left(r^{2}=-0.93, p<0.01\right)$, Luteimonas $\left(r^{2}=-0.87, p<0.01\right)$, Rhodanobacter $\left(r^{2}=-0.75, \quad p<0.01\right)$, Sphingomonas, $\left(r^{2}=-0.68, \quad p<0.05\right), \quad$ Gemmatimonas $\quad\left(r^{2}=-0.63\right.$, $p<0.05)$, Flavobacterium $\left(r^{2}=-0.54, p<0.05\right)$, and Leifsonia $\left(r^{2}=-0.56, p<0.05\right)$ were negatively correlated with the remained concentration of phenanthrene in soil. 


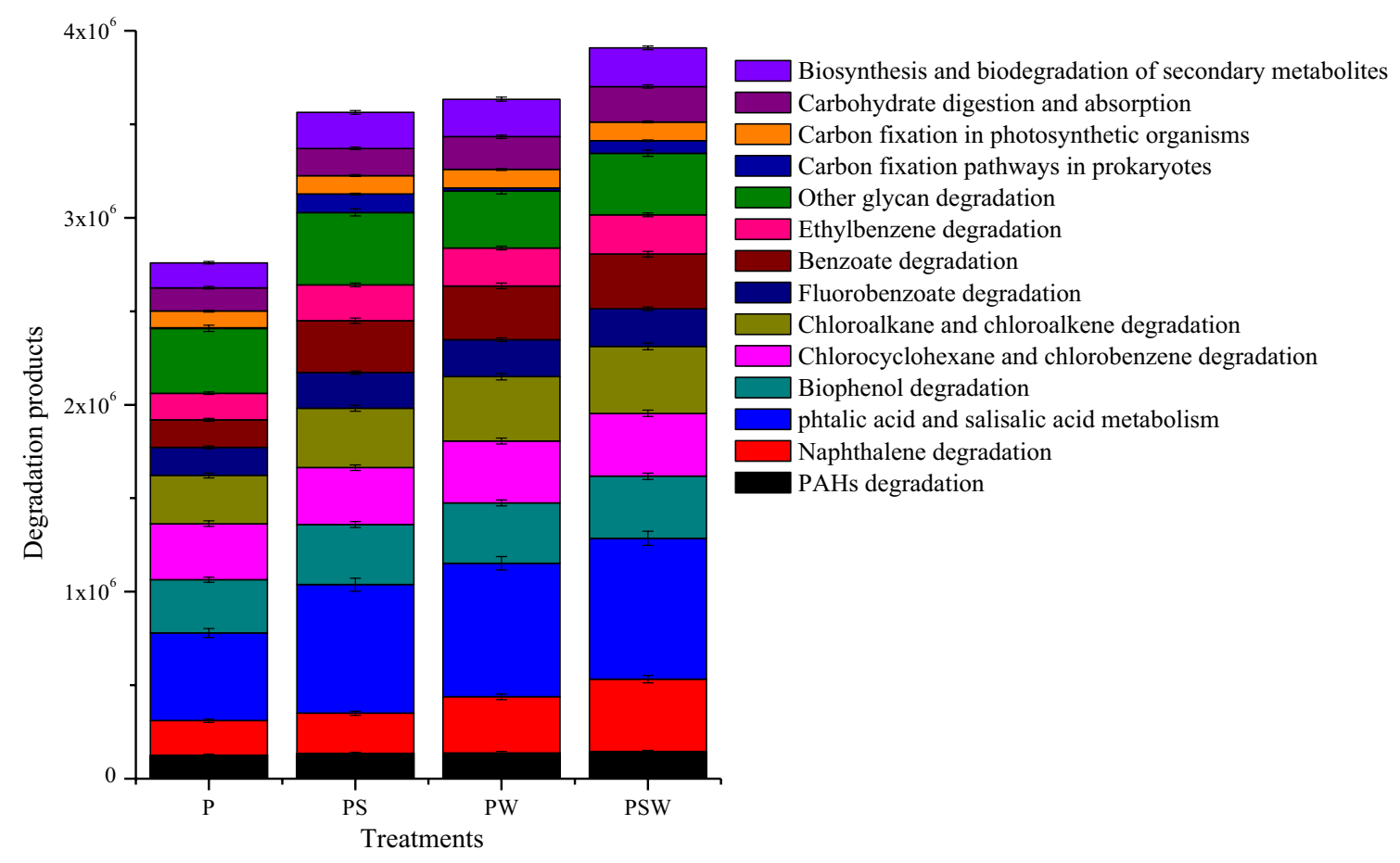

Fig. 2 Different organic products identified in the different soil samples. The horizontal axis represents the number of each sample, the vertical axis represents the abundance ratio and the error bar represented the standard. The color corresponds to the function name and different color width indicates different function abundance. (P control treatment, PS rice straw treatment, PW earthworm treatment and PSW $=$ combined earthworms and straw treatment)

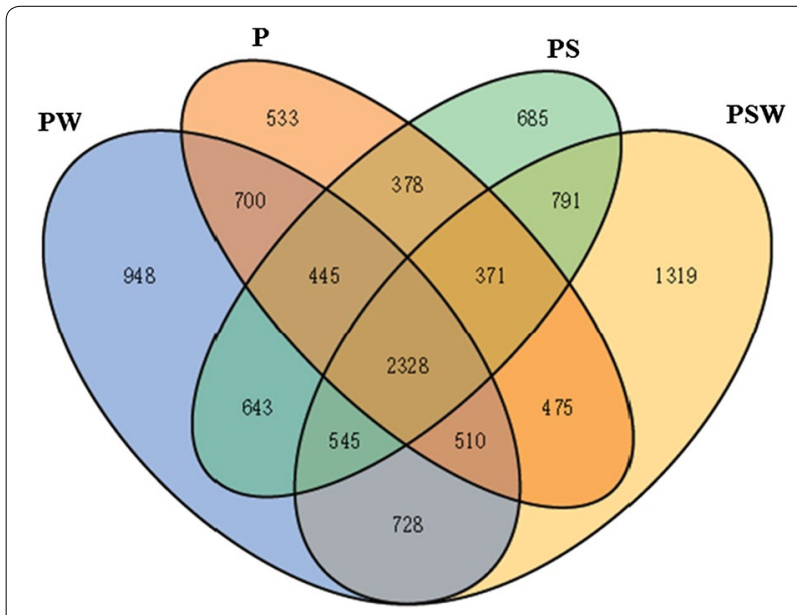

Fig. 3 A Venn diagram displaying the degree of intersection of bacterial OTUs clustered at $97 \%$ sequence similarity among the different treatments. Different samples display different color, number in the diagram represents the shared or unique OTU number. Overlap region represents shared OTU number, while non-overlap region represents unique OTU number. The OTUs differed among the four treatments and their numbers were 5740 (P), 6186 (PS), 6847 (PW) and 7067 (PSW). $P$ is the control treatment (none straw neither earthworms), PS is treatment with rice straw, PW is the treatment with earthworms and PSW is the treatments with both rice straw and earthworms
Principal component analysis (PCoA) expounded bacterial community structure

Based on the presence or absence of phylotype in the four treatments, the unweighted principal component analysis (PCoA) was performed and the result is reported in Fig. 5. More particularly, earthworms (PW) and combined (PSW) treatments presented PC1 values much higher than those of the control $(P)$ and straw (PS) treatments. The community structure of bacteria in earthworm treatment (PW and PSW) was distinguished and clustered together. Thus, the result of this PCoA strongly accentuated that both earthworms and straw and especially earthworms are a booster factor in the formation of the bacterial community, responsible for the removal of phenanthrene.

\section{Relative abundance between straw and earthworm treatments}

To further investigate the bacterial taxa distinct among earthworms and straw groups, LEfSe analysis and LDA was performed (Fig. 6). The circle, from internal to external, indicates bacteria from phylum to genus, respectively. Yellow points represent bacteria that have no significant differences from each other, and specific 

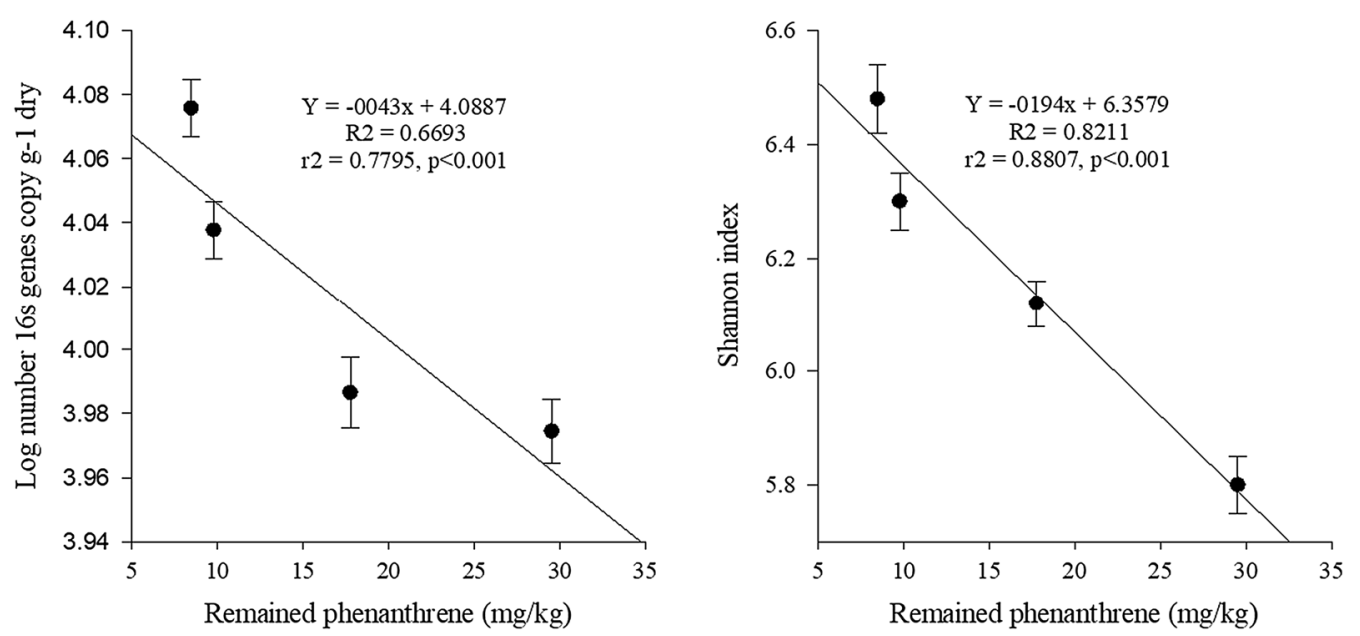

Fig. 4 Correlation between remained phenanthrene concentration in the soil and the soil bacteria 16S rRNA genes and bacteria Shannon index. Remained phenanthrene concentration had a significant correlation with the soil bacteria $16 \mathrm{~S} r R N A$ genes $(r 2=-07795, p<0.001)$ and bacterial Shannon index $(r 2=-0.8807, \mathrm{p}<0.001)$

Table 2 Pearson's correlation coefficient relating to phenanthrene and the relative abundance of bacterial groups at class and genus level, respectively

\begin{tabular}{llll}
\hline Classification level & Bacterial group & Percentage & Person's correlation coefficient \\
\hline Class & Gamma-proteobacteria & 30 & $r^{2}=-0.81, p<0.01$ \\
& Alpha-proteobacteria & $r^{2}=-0.74, p<0.01$ & $r^{2}=-0.56, p<0.05$ \\
& Sphingobacteria & 15 & $r^{2}=-0.52, p<0.05$ \\
& Actinobacter & 25 & $r^{2}=-0.61, p<0.05$ \\
& Gemmatimonadetes & 20 & $r^{2}=-0.581, p<0.05$ \\
Glavobacteria & 12 & $r^{2}=-0.54, p<0.05$ \\
& Cytophagia & 7 & $r^{2}=-0.68, p<0.05$ \\
& Sphingomonas & 7 & $r^{2}=-0.87, p<0.01$ \\
& Luteimonas & 34.7 & $r^{2}=-0.75, p<0.01$ \\
& Rhodanobacter & 24.63 & $r^{2}=-0.63, p<0.05$ \\
& Gemmatimonas & 21.34 & $r^{2}=-0.93, p<0.01$ \\
& Pseudomonas & 15.65 & $r^{2}=-0.54, p<0.05$
\end{tabular}

bacteria are colored by their corresponding class color. The LDA score of different specific bacteria and LEfSe applied to the microbiota data of rice straw and earthworms' samples found 13 differentially abundant taxonomic clades with an LDA score higher than 3.5. It was revealed that the higher taxonomic levels of Bacteroidetes and Proteobacteria (including Sphingobacteria/Alphaproteobacteria and Betaproteobacteria, respectively) were significantly less abundant in straw groups, whereas the Flavobacteria class, Rhodobacterales order, Firmicutes and Actinobacteria phylum were less abundant in earthworm groups.

\section{Discussion}

The investigation of the impacts of earthworms and rice straw on phenanthrene degradation and soil microbial community was conducted in this present study. The results showed that rice straw and earthworms not only improve the soil structure and phenanthrene degradation, but also interacted each other and changed the soil microbial community and structure.

\section{Phenanthrene degradation}

Phenanthrene concentration decreased when earthworms were applied (Table 1), indicating that the 


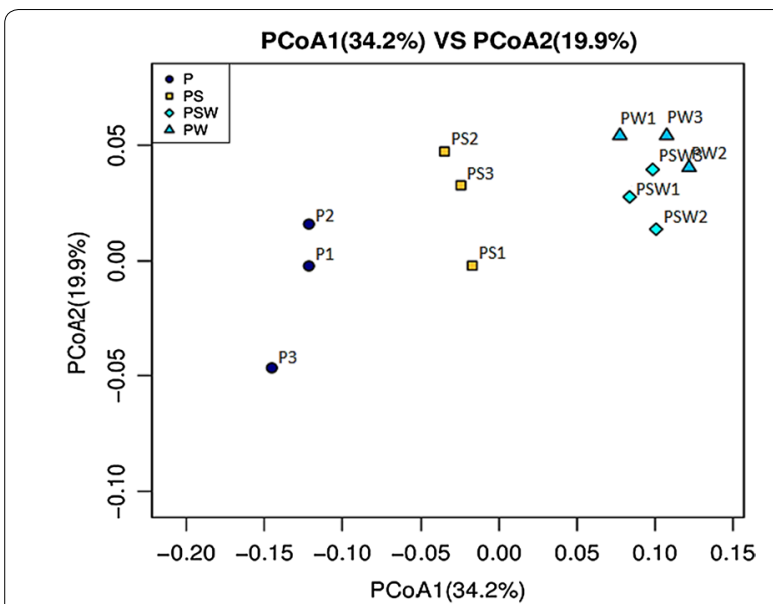

Fig. 5 PCoA showing the bacterial community grouping. Different color represents different samples or groups. The more similarity between samples, the more gathered in the figure. PSW and PW treatments showed obvious difference in the bacterial community compared $P$ treatments. $P$ control treatment, $P S$ rice straw treatment, $P W$ earthworm treatment and PSW combined earthworms and straw treatment

degradation, sorption and/or transformation of phenanthrene could produce. Information about functional genes disclosed that carbohydrate metabolism including bisphenol, benzoate and ethylbenzene degradation was more enriched in soil samples, indicating that both rice straw and earthworm enhanced phenanthrene degradation (Figs. 1and 2). Xenia and Refugio [43] reported that the interactions between enzymes that degrade phenanthrene and modify its structure as well as its toxicity are determining for microbial phenanthrene degradation. Specific microorganisms, through multienzyme complex, oxidize the carbon molecules and incorporate an oxygen molecule, resulting in a hydroxylated carbon to alcohol [52]. Subsequently, the alcohol group is oxidized to aldehyde and finally to carboxylic acid [38]. This could explain the enrichment of phenol and benzoate degradation in this present study. Earthworms are reported to stimulate phenanthrene removal by promoting soil phenanthrene degrading microorganism $[9,34]$. Similarly, in the present study, in the presence of earthworms, it was found that phenanthrene degradation correlated with the increase of soil microbial community. The ratio of phenanthrene remained in soil significantly decreased in PW and PSW treatments (Table 1), indicating to more efficiency of earthworm implication on the decrease of phenanthrene concentration. Thus, our results reaffirm previous reports that earthworms could enhance PAH degradation.

\section{Changes in microbial community and phenanthrene degradation in the soil Induced by earthworms}

Earthworms were reported to accelerate the removal diver organic pollutant including PAHs [9]. Earthworms enhance $\mathrm{PAH}$ degradation by stimulating microbial

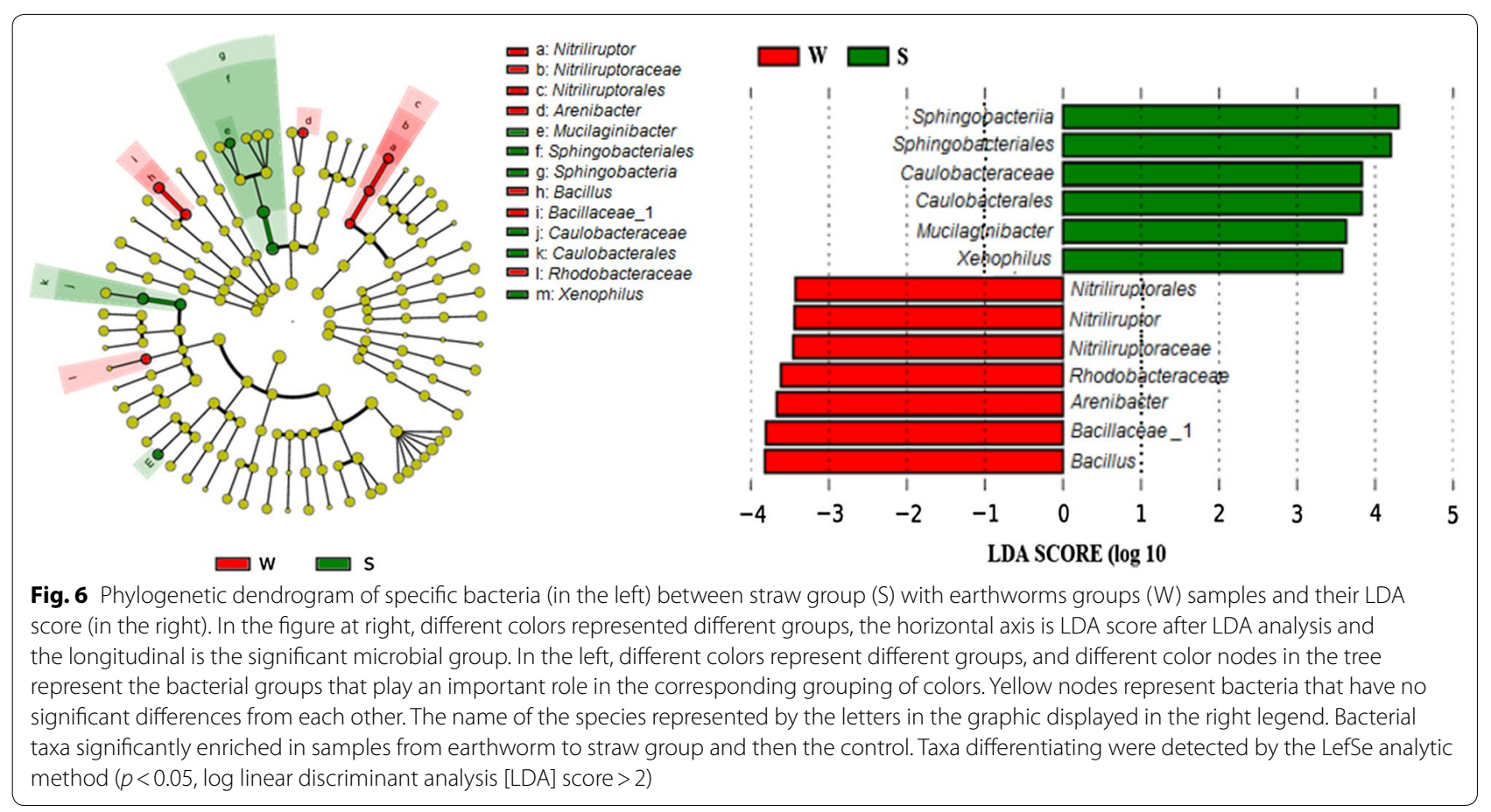


growth and thereby affect the soil microbial community [45]. The addition of earthworms either in separate (PW) or dual (PSW) treatments revealed to play a key role on the formation of the bacterial community in soil. This observation was confirmed by the significant difference observed in PCoA value in this present study (Fig. 5). Soil bacterial abundance was remarkably increased in PW and in PSW treatments. These results indicated that earthworms might improve the phenanthrene degradation by increasing soil bacteria biomass and diversity. The addition of earthworm strongly stimulated the growth of Proteobacteria phylum which was largely dominant. Proteobacteria composed by alpha, gamma, beta and deltaproteobacteria is one of the most frequently isolated phyla from the contaminated environments and reported able to degrade PAHs such as naphthalene, anthracene and phenanthrene by complete mineralization via similar pathways $[6,27,29]$. Sphingomonas strains such as $S$. koreensis, Sphingobium sp., Novosphingobium pentaromativorans, Sphingopyxis sp., Rhizobiales strains such as Sinorhizobium sp., Ochrobactrum sp. and Pseudomonas strains such as $P$. aeruginosa, Pseudomonas. sp. and $P$. putida have been reported to degrade phenanthrene [37, 47]. Additionally, some Actinobacteria phylum strains such as Mycobacterium sp., M. vanbaalenii and M. fortuitum and some Flavobacteria strains were also shown with high efficiency to degrade phenanthrene [42]; [20]. In this present study, the abundance of Pseudomonas, Luteimonas and Rhodanobacter significantly increased in the PW and PSW treatment (Table 2). This suggested that earthworm's activities stimulated their growth. In addition, these genera negatively correlated with the remained phenanthrene in soil. This indicated that Pseudomonas, Luteimonas and Rhodanobacter were not only involved in the phenanthrene degradation but also were the most beneficial phenanthrene degraders.

\section{Induced by rice straw}

Many agricultural management practices such as fertilization, tillage, and straw return significantly influence soil organic matter which is the midpoint of soil function and quality [50]. Rice straw addition increased soil microorganisms, which in return play key roles in organic matter decomposition and soil nutrient biogeochemical cycling such as carbon and nitrogen in ecosystems $[16,53]$. The litter alteration including fragmentation and consumption of associated microorganisms usually increases the microbial activity [15, 32]. However, soil microbial community structure was reported to vary with agricultural management practices and its application time [5]. Rice straw showed a positive influence on phenanthrene removal by increasing significantly the abundance of $16 \mathrm{~S}$ rRNA genes while having no effect on bacterial Shannon index (Table 1). Studies reported that the use of organic fertilizers likely played a critical role in the degradation and removal of organic contaminant in soil [41]. It can be speculated that the phenanthrene removal in rice straw treatment was strongly assessed by soil microbial stimulated by rice straw decomposition activities rather than rice straw itself. Rice straw as organic fertilizer influences microbial population in soil through stimulatory and suppressive effects on specific components and impacts the whole community structure [2]. Crop residue retention was reported to significantly affect bacterial community structure and increased the abundances of Bacteroidetes, Betaproteobacteria, and Gemmatimonadetes [31]. Sphingomonas, Luteimonas, Gemmatimonas and Flavobacterium showed significant negative correlation with the remained phenanthrene in soil (Table 2). This indicates that rice straw would accelerate the degradation of phenanthrene by stimulating the growth and the abundance of these bacteria in soil.

\section{Induced by the combination of earthworms and rice straw}

Several PAH bioremediation process, involving biostimulation application, focused on the complex interaction between earthworms and soil microbial community. However, the organic fertilizer rice straw can be involved in PAH removal. Very little information is available concerning the implication of crops straw on PAH removal in general and how earthworms interact with crops straw and affect the microbial degradation of PAHs in particular. Thus, in the present study, it is shown that earthworms and rice straw can increase the transformation rate of phenanthrene which may fulfil the aim of the bioremediation approach. The coexistence of earthworms and rice straw in this study significantly increased the abundance of bacteria $16 \mathrm{~S}$ rRNA and bacterial Shannon index (Table 1). Additionally, the introduction of earthworms and rice straw in soil had the lowest phenanthrene remained ratio (Table 1), the lowest phenanthrene remained concentration (Table 1) and the higher abundance of some specific bacteria such as Sphingomonas, Rhodanobacter and Pseudomonas (Table 2). The dual rice straw and earthworms introduction in soil had the soil remained phenanthrene concentration negatively correlated with the soil bacterial 16S rRNA genes and bacterial Shannon index (Fig. 4). Considering these results, this study highlights that the ecological context of remediation should not be limited on soil-earthworms-plant interaction only, but should be extended by integrating the natural resources forsaken which can provide a positive influence on soil microorganisms' changes and enhance PAH degradation in soil. 


\section{Conclusion}

This study demonstrates the positive interaction between earthworms and rice straw in soil. Their co-existence with soil microbial interactively improves the degradation of phenanthrene in soil. Both earthworms and rice straw stimulate the abundance of specific bacteria which showed strong and clear correlation with the phenanthrene concentration in soil. What it should be noted is that this study established that earthworms and rice straw could quicken phenanthrene degradation by changing bacterial growth and community configuration in the soil. The variation in soil nutrients and structure by earthworms and rice straw addition enable to modify the structure of the microbial community. From this present study, it can be seen, the importance of the neglected natural resources like rice straw and how this later can interact with the soil macro- and microorganisms to change soil structure and enhance PAH degradation in soil.

\section{Supplementary information}

Supplementary information accompanies this paper at https://doi. org/10.1186/s12302-020-00400-y.

Additional file 1: Table S1. Estimation of bacterial abundance and diversity indices in different treatments extract control treatments. Seq_num is the quality number of samples reads and OTU_num is the number of $16 \mathrm{~S}$ rRNA sequences OTUs obtained by sample clustering and normalized SPSS. Figure S1. Relative abundance of soil bacterial (grouping of the three replicates of each soil samples) at phylum level. The horizontal axis represents the treatment and the vertical axis represents the abundance ratio in percentage. The color corresponds to the phylum name and different color width indicates different phylum. (-Ck = control without acetone and $+\mathrm{Ck}=$ control with acetone). Figure S2. Relative abundance of soil bacterial (in replicate form of each soil samples) at phylum level. The horizontal axis represents the treatment and the vertical axis represents the abundance ratio in percentage. The color corresponds to the phylum name and different color width indicates different phylum. (-Ck = control without acetone and $+\mathrm{Ck}=$ control with acetone). Figure S3. Relative abundance of soil bacterial (grouping of the three replicates of each soil samples) at order level. The horizontal axis represents the treatment and the vertical axis represents the abundance ratio in percentage. The color corresponds to the phylum name and different color width indicates different phylum. (-Ck = control without acetone and $+C k=$ control with acetone). Figure S4. Relative abundance of soil bacterial (in replicate form of each soil samples) at order level. The horizontal axis represents the treatment and the vertical axis represents the abundance ratio in percentage. The color corresponds to the phylum name and different color width indicates different phylum. (-Ck $=$ control without acetone and $+\mathrm{Ck}=$ control with acetone). Table S2. Data are the mean of three replicate \pm SD and were compared by Duncan's multiple range tests. Seq_num is the quality number of samples reads and 16S rRNA num is the number of $16 \mathrm{~S}$ rRNA sequences obtained by sample clustering and normalized PICRUSt.

\section{Abbreviations}

HZAU: Huazhong Agricultural University; HPLC: High-performance liquid chromatography; PAH: Polycyclic aromatic hydrocarbons; PPPAH: Priority pollutant polycyclic aromatic hydrocarbons.

\section{Acknowledgements}

Authors are thankful to Professor Critina Giacomafrom of Department of Animal Biology and Human of the University of Turin, Italy, for providing valuable advice to ameliorate this work. The authors gratefully acknowledge the laboratory staff members for their remarkable supports.

\section{Authors' contributions}

AME designed and performed the study; $\mathrm{CH}$ supervised and funded the project. Both authors read and approved the final manuscript.

\section{Authors' information}

Dr. Ali Mohamed Elyamine, post doctor at Shantou University, in Environmental engineering \& pollution management; ecology, sustainability development and biodiversity conservation; soil sciences; soil ecology; soil biology; soil fertilizers; environmental remediation, bioremediation and phytoremediation; environmental stress; soil analysis, soil chemistry and sustainable agriculture.

\section{Funding}

This work was supported by the National Natural Science Foundation of China (Program No. 41271275).

\section{Availability of data and materials \\ Not applicable.}

Ethics approval and consent to participate

Not applicable.

\section{Consent for publication}

Not applicable.

\section{Competing interest}

Authors declare no competing financial interest.

\section{Author details}

${ }^{1}$ Key Laboratory of Arable Land Conservation (Middle and Lower Reaches of Yangtze River), Ministry of Agriculture, Research Center of Micro-elements, College of Resource and Environment, Huazhong Agricultural University, Wuhan 430070, Hubei, China. ${ }^{2}$ Hubei Provincial Engineering Laboratory for New Fertilizers, Huazhong Agricultural University, Wuhan 430070, Hubei, China. ${ }^{3}$ Faculty of Science and Technology, Department of Life Science, University of Comoros, Moroni 269, Comoros.

Received: 22 February 2020 Accepted: 14 September 2020 Published online: 01 October 2020

\section{References}

1. Bain DJ, Yesilonis ID, Pouyat RV (2012) Metal concentrations in urban riparian sediments along an urbanization gradient. Biogeochemistry 107(1-3):67-79

2. Cao J, Wang C, Dou Z, Liu M, Ji D (2018) Hyphospheric impacts of earthworms and arbuscular mycorrhizal fungus on soil bacterial community to promote oxytetracycline degradation. J Hazard Mater 341:346-354

3. Cébron A, Louvel B, Faure P, France-Lanord C, Chen Y, Murrell JC, Leyval C (2011) Root exudates modify bacterial diversity of phenanthrene degraders in PAH-polluted soil but not phenanthrene degradation rates. Environ Microbiol 13:722-736

4. Cheema SA, Khan MI, Tang X, Zhang C, Shen C, Malik Z, Ali S, Yang J, Shen K, Chen X (2009) Enhancement of phenanthrene and pyrene degradation in rhizosphere of tall fescue (Festuca arundinacea). J Hazard Mater 166:1226-1231

5. Chen Z, Wang H, Liu X, Zhao X, Lu D, Zhou J, Li C (2017) Changes in soil microbial community and organic carbon fractions under short-term straw return in a rice-wheat cropping system. Soil Til Res 165:121-127

6. Crampon M, Cébron A, Portet-Koltalo F, Uroz S, Le Derf F, Bodilis J (2017) Low effect of phenanthrene bioaccessibility on its biodegradation in diffusely contaminated soil. Environ Pollut 225:663-673

7. Cristaldi A, Conti GO, Jho EH, Zuccarello P, Grasso A, Copat C, Ferrante $M$ (2017) Phytoremediation of contaminated soils by heavy metals and PAHs A brief review. Environ Technol Innov 8:309-326

8. Davidova IA, Gieg LM, Ducan KE, Sulfita JM (2007) Anaerobic phenanthrene mineralization by a carboxylating sulfate-reducing bacterial enrichment. ISME J 48(1):436-442 
9. Dendooven L, Alvarez-Bernal D, Contreras-Ramos SM (2011) Earthworms, a means to accelerate removal of hydrocarbons (PAHs) from soil? A minireview. Pedobiologia 54:S187-S192

10. Deng D, Lin X, Ou J, Wang Z, Li S, Deng M, Shu Y (2015) Efficient chemical oxidation of high levels of soil-sorbed phenanthrene by ultrasound induced, thermally activated persulfate. Chem Eng J 265:176-183

11. Dittbrenner N, Moser I, Triebskorn R, Capowiez Y (2011) Assessment of short and long-term effects of imidacloprid on the burrowing behaviour of two earthworm species (Aporrectodea caliginosa and Lumbricus terrestris) by using $2 \mathrm{D}$ and $3 \mathrm{D}$ post-exposure techniques. Chemosphere 84(10):1349-1355

12. Elyamine A, Afzal J, Rana M, Imran M, Cai M, Hu C (2018) Phenanthrene mitigates cadmium toxicity in earthworms Eisenia fetida (Epigeic Specie) and Aporrectodea caliginosa (Endogeic Specie) in soil. J Environ Res Public Health 15(11):2384

13. Elyamine A, Moussa M, Ismael M, Wei J, Zhao Y, Wu Y, Hu C (2018) Earthworms, rice straw, and plant interactions change the organic connections in soil and promote the decontamination of cadmium in soil. Int J Environ Res Public Health 15(11):2398

14. Fan J, Xiao J, Liu D, Ye G, Luo J, Houlbrooke D, Laurenson S, Yan J, Chen L, Tian J (2017) Effect of application of dairy manure, effluent and inorganic fertilizer on nitrogen leaching in clayey fluvo-aquic soil: a lysimeter study. Sci Tot Environ 592:206-214

15. Frouz J (2017) Effects of soil macro-and mesofauna on litter decomposition and soil organic matter stabilization. Geoderma

16. Grandy AS, Salam DS, Wickings K, MCDaniel MD, Culman SW, Snapp SS (2013) Soil respiration and litter decomposition responses to nitrogen fertilization rate in no-till corn systems. Agric Ecosyst Environ 179:35-40

17. Haritash AK, Kaushik CP (2009) Biodegradation aspects of polycyclic aromatic hydrocarbons (PAHs): a review. J Hazard Mater 169:1-15

18. Huang J, Li Z, Nie X, Zhang J, Tang Z, Ma W, Yu W, Zeng G (2014) Microbial responses to soil rewetting in erosional and depositional environments in relation to the organic carbon dynamics. Geomorphology 204:256-264

19. Huang M, Li Z, Huang B, Luo N, Zhang Q, Zhai X, Zeng G (2018) Investigating binding characteristics of cadmium and copper to DOM derived from compost and rice straw using EEM-PARAFAC combined with twodimensional FTIR correlation analyses. J Hazard Mater 344:539-548

20. Jacques RJ, Okeke BC, Bento FM, Teixeira AS, Peralba MC, Camargo FA (2008) Microbial consortium bioaugmentation of a polycyclic aromatic hydrocarbons contaminated soil. Bioresour Technol 99(7):2637-2643

21. Khan Ml, Hayat T, Waqas M, Khan MI, Alsaedi A (2017) Impact of heat generation/absorption and homogeneous-heterogeneous reactions on flow of Maxwell fluid. J Mol Liq 233:465-470

22. Kim Y-N, Robinson B, Lee K-A, Boyer S, Dickinson N (2017) Interactions between earthworm burrowing, growth of a leguminous shrub and nitrogen cycling in a former agricultural soil. App Soil Eco 110:79-87

23. Lim SL, WU TY, Sim EYS, Lim PN, Clarke C (2012) Biotransformation of rice husk into organic fertilizer through vermicomposting. Ecol Eng 41:60-64

24. Lin C-W, Chen L-H, Yet-Pole I, Lai C-Y (2010) Microbial communities and biodegradation in lab-scale BTEX-contaminated groundwater remediation using an oxygen-releasing reactive barrier. Bioprocess Biosyst Eng 33(3):383-391

25. Lin Z, Bai J, Zhen Z, Lao S, Li W, Wu Z, Li Y, Spiro B, Zhang D (2016) Enhancing pentachlorophenol degradation by vermicomposting associated bioremediation. Ecol Eng 87:288-294

26. Lin Z, Zhen Z, Ren L, Yang J, Luo C, Zhong L, Hu H, Liang Y, Li Y, Zhang $D$ (2017) Effects of two ecological earthworm species on atrazine degradation performance and bacterial community structure in red soil. Chemosphere

27. Ma L, Xie Y, Han Z, Giesy JP, Zhang X (2017) Responses of earthworms and microbial communities in their guts to Triclosan. Chemosphere 168:1194-1202

28. Maigari AU, Maigari MU (2015) Microbial metabolism of polycyclic aromatic hydrocarbons (PAHs): a review. Int J Sci Eng 6:1449-1459

29. Mora P, Seugé C, Chotte J, Rouland C (2003) Physico-chemical typology of the biogenic structures of termites and earthworms: a comparative analysis. Biol Fertil Soil 37(4):245-249

30. Morillo E, Villaverde J (2017) Advanced technologies for the remediation of pesticide-contaminated soils. Sci Total Eviron 586:576-597

31. Navarro-Noya YE, Gómez-Acata S, Montoya-Ciriaco N, Rojas-Valdez A, Suárez-Arriaga MC, Valenzuela-Encinas C, Jiménez-Bueno N, Verhulst N,
Govaerts B, Dendooven L (2013) Relative impacts of tillage, residue management and crop-rotation on soil bacterial communities in a semi-arid agroecosystem. Soil Biol Biochem 65:86-95

32. Pant M, Negi GC, Kumar P (2017) Macrofauna contributes to organic matter decomposition and soil quality in Himalayan agroecosystems, India. Appl Soil Ecol 120:20-29

33. Rocha CG, Zaia DAM, da Silva Alfaya RV, da Silva Alfaya AA (2009) Use of rice straw as biosorbent for removal of $\mathrm{Cu}(\mathrm{II}), \mathrm{Zn}$ (II), Cd (II) and Hg(II) ions in industrial effluents. J Hazard Mater 166(1):383-388

34. Rodriguez-Campos J, Dendooven L, Alvarez-Bernal D, Contreras-Ramos SM (2014) Potential of earthworms to accelerate removal of organic contaminants from soil: a review. Appl Soil Ecol 79:10-25

35. Rupani PF, Singh RP, Ibrahim MH, Esa N (2010) Review of current palm oil mill effluent (POME) treatment methods: vermicomposting as a sustainable practice. World Appl Sci J 11:70-81

36. Singer A, Jury W, Luepromchai E, Yahng C-S, Crowley D (2001) Contribution of earthworms to PCB bioremediation. Soil Biol Biochem 33:765-776

37. Sun K, Liu J, Gao Y, Sheng Y, Kang F, Waigi MG (2015) Inoculating plants with the endophytic bacterium Pseudomonas sp. Ph6-gfp to reduce phenanthrene contamination. Environ Sci Pollut Res 22(24):19529-19537

38. Szczepaniak Z, Czarny J, Staninska-Pięta J, Lisiecki P, Zgoła-Grześkowiak A, Cyplik P, Chrzanowski Ł, Wolko Ł, Marecik R, Juzwa W (2016) Influence of soil contamination with PAH on microbial community dynamics and expression level of genes responsible for biodegradation of $\mathrm{PAH}$ and production of rhamnolipids. Environ Sci Pollut Res 23(22):23043-23056

39. Teng Y, Wang X, Li L, Li Z, Luo Y (2015) Rhizobia and their bio-partners as novel drivers for functional remediation in contaminated soils. Front Plant Sci 6:32

40. Waigi MG, Kang F, Goikavi C, Ling W, Gao Y (2015) Phenanthrene biodegradation by sphingomonads and its application in the contaminated soils and sediments: a review. Int Biodeterior Biodegrad 104:333-349

41. Włóka D, Placek A, Rorat A, Smol M, Kacprzak M (2017) The evaluation of polycyclic aromatic hydrocarbons (PAHs) biodegradation kinetics in soil amended with organic fertilizers and bulking agents. Ecotoxicol Environ Saf 145:161-168

42. Wu M, Nie M, Wang X, Su J, Cao W (2010) Analysis of phenanthrene biodegradation by using FTIR, UV and GC-MS. Spectrochim Act P A Mol Biomol Spectrosc 75(3):1047-1050

43. Xenia M, Refugio R (2016) Microorganisms metabolism during bioremediation of oil contaminated soils. J Bioremed Biodegrad 7(340):2

44. Xiao H, Li Z, Dong Y, Chang X, Deng L, Huang J, Nie X, Liu C, Liu L, Wang D (2017) Changes in microbial communities and respiration following the revegetation of eroded soil. Agric Ecol Environ 246:30-37

45. Yang C-W, Tang S-L, Chen L-Y, Chang B-V (2014) Removal of nonylphenol by earthworms and bacterial community change. Int Biodeterior Biodegrad 96:9-17

46. Yang $X$, Lv Z, Bian Y, Wang F, Gu C, Song Y, Jiang X (2013) Predicting PAHs bioavailability for earthworms by mild solvents and Tenax extraction. J Environ Chem Eng 1(4):768-776

47. Yongping J, Yan L, Zhaohui L, Zhang Y, Ping S, Ming, Jiafa L (2017) Effects of bacterial-feeding nematodes and glucose on phenanthrene removal by Pseudomonas putida. Pedosphere 27(1):165-171

48. Yuan Q, Hernández M, Dumont MG, Rui J, Scavino AF, Conrad R (2018) Soil bacterial community mediates the effect of plant material on methanogenic decomposition of soil organic matter. Soil Biol Biochem 116:99-109

49. Zhang L, Zhang S, Lv X, Qiu Z, Zhang Z, Yan L (2018) Dissolved organic matter release in overlying water and bacterial community shifts in biofilm during the decomposition of Myriophyllum verticillatum. Sci Tot Environ 633:929-937

50. Zhao S, Li K, Zhou W, Qiu S, Huang S, He P (2016) Changes in soil microbial community, enzyme activities and organic matter fractions under long-term straw return in north-central China. Agric Ecol Environ 216:82-88

51. Zhi-Ming S, Li X, Feng H (2014) A hierarchic method for studying the distribution of phenanthrene in Eisenia fetida. Pedosphere 24(6):743-752

52. Zhong Y, Wang J, Carmella SG, Hochalter JB, Rauch D, Oliver A, Jensen J, Hatsukami DK, Upadhyaya P, Zimmerman C (2011) Metabolism of [D10] phenanthrene to tetraols in smokers for potential lung cancer susceptibility assessment: comparison of oral and inhalation routes of administration. J Pharm Exp Ther 338(1):353-361 
53. Zhu L, Hu N, Zhang Z, Xu J, Tao B, Meng Y (2015) Short-term responses of soil organic carbon and carbon pool management index to different annual straw return rates in a rice-wheat cropping system. CATENA 135:283-289

\section{Publisher's Note}

Springer Nature remains neutral with regard to jurisdictional claims in published maps and institutional affiliations.
Submit your manuscript to a SpringerOpen ${ }^{\circ}$ journal and benefit from:

- Convenient online submission

- Rigorous peer review

- Open access: articles freely available online

- High visibility within the field

- Retaining the copyright to your article

Submit your next manuscript at $\boldsymbol{\nabla}$ springeropen.com 